\title{
DIREITO FUNDAMENTAL À CIDADE SUSTENTÁVEL E OS DILEMAS DO PLANEJAMENTO URBANO NO ESTADO DEMOCRÁTICO DE DIREITO*
}

\author{
FUNDAMENTAL RIGHT TO A SUSTAINABLE CITY AND THE DILEMMAS OF THE URBAN \\ PLANNING IN THE DEMOCRATIC STATE OF LAW
}

\author{
Gabriele Araújo Pinheiro* \\ Wagner de Oliveira Rodrigues, MSc ${ }^{* * *}$
}

\begin{abstract}
Resumo:
No bojo das inovações pertinentes ao direito urbanístico trazidas pelo Estado Democrático de Direito, o presente artigo objetiva abordar o direito fundamental à cidade sustentável seguindo pelos meandros de sua relação com o princípio fundamental da dignidade da pessoa humana, uma vez que o ambiente citadino se caracteriza, essencialmente, por ser espaço político, social, cultural e filosófico, em que é possível o desenvolvimento das potencialidades humanas. Nesse sentido, é realizado um estudo sobre os diferentes institutos jus-urbanísticos em vigor no ordenamento jurídico pátrio, conferindo especial ênfase à Lei Federal 10.257 autodenominada Estatuto da Cidade - ao Plano Diretor Municipal, assim como as mudanças paradigmáticas ocorridas com a positivação da função social da cidade e da propriedade na Constituição da República federativa do Brasil.
\end{abstract}

Palavras-chave: Direito Fundamental à Cidade Sustentável. Estado Democrático de Direito. Plano Diretor Municipal.

\begin{abstract}
:
In the field of the inovations, concerned at Urbanist Law, brought by Democratic State of Law, the present article aims to attack the fundamental Law at the sustainable city following meanders of its relation with the fundamental principle of the dignity of the human person, because the urban space characterizes itself, essentially, for being a politic, social, cultural and philosophic space, where the development of the human potentialities is possible. So a study about the different institutes of Urbanist Law in the vigour in paternal juridical order is achieved, giving especial emphasis to federal Law 10.257, denominated Statute of the City, and at the Municipal Director Plan, as paradigmatic changes occurred with the positivity of the social function of the city and of the propriety in the Constitution of the Federative Republic from Brazil.
\end{abstract}

Keywords: Fundamental Law at the Sustainable City. Democratic State of Law. Municipal Director Plan.

* Matéria redatorial indicada pelo Editor, aprovada pela Comissão de Publicação, em 2012.

** Discente do Curso de Direito da Universidade Estadual de Santa Cruz; membro do Grupo de Pesquisa em Direitos Humanos e Fundamentais na Linha de Pesquisa "Sustentabilidade Ambiental e Acesso à Cidade", pesquisadora de iniciação científica e estagiária de Direito da Defensoria Pública.

*** Docente dos Cursos de Direito da Universidade Estadual de Santa Cruz e da Faculdade de Ilhéus - CESUPI; líder e membro do Grupo de Pesquisa em Direitos Humanos e Fundamentais na Linha de Pesquisa "Sustentabilidade Ambiental e Acesso à Cidade" e advogado. 
Introdução

Com o advento da instituição do Estado Democrático de Direito na República Federativa do Brasil o Ordenamento Jurídico Pátrio foi irradiado por novos institutos que visam à superação do processo histórico, altamente excludente, de construção das cidades brasileiras. O clamor social motivado pelo caos vivido nas grandes cidades brasileiras na segunda metade do século XX pressionou o constituinte a reservar no Texto Magno um capítulo especificamente para tratar da política urbana.(CARVALHO FILHO, 2007, p. ix)

Por esse viés, foi atribuído por via constitucional ao Poder Público, em cooperação com a sociedade civil e entidades privadas, a árdua tarefa de repensar, planejar e fornecer mecanismos de concretização dos direitos pertinentes aos espaços citadinos, dentre eles o direito fundamental à cidade sustentável, que implica uma série de transformações na forma de produção e consumo das cidades, ampliando as dimensões dos mecanismos citadinos para toda a população, com o intuito de abranger, em especial, áreas urbanas marginais, assim como as populações rurais ou semi-rurais que se localizam no entorno dos centros urbanizados e consomem os mecanismos da cidade.

Sendo assim, com o escopo de alcançar a efetivação dos novos institutos jus-urbanísticos, a Constituição de 1988 prevê a elaboração de leis de âmbito federal (Lei Federal 10.257/2001) e municipal (Plano Diretor Municipal), para a regulamentação da política de desenvolvimento e expansão urbana, ao passo que estabelece princípios que passarão a orientar o direito urbanístico, a exemplo da função social da cidade e da propriedade urbana, justiça social, equidade e gestões democráticas das cidades, os quais serão caracterizados e analisados alhures.

\section{Breve contextualização histórico-legal das cidades no Brasil}

A atual mobilização acerca da necessidade de se planejar, ordenar e realizar as diretrizes de Direito Urbanístico no território brasileiro deve-se, basicamente, à falta de infra-estrutura e de mecanismos citadinos necessários à vida e ao desenvolvimento humano. A história de construção das cidades brasileiras aponta para uma trajetória marcada por ações isoladas em defesa dos interesses das elites dominantes, em destaque a elite agrária, já que o seu poderio está diretamente ligado ao fato de que as primeiras cidades, a exemplo de Salvador, Olinda e Rio de Janeiro, surgiram como núcleos coloniais, cujo escopo estava vinculado à defesa e exploração das terras do Brasil, então colônia de Portugal. (LEAL, 2003, p.15-16)

A chegada da família real portuguesa ao Brasil em 1808, a abertura dos portos ao comércio externo e a independência do Brasil em 1822, deram os primeiros passos para o crescimento das cidades brasileiras e contribuíram para a realização de 
alguns melhoramentos urbanos, a exemplo de aterros, fornecimento de água às residências, pavimento de novas ruas e criação de rodovias para escoamento do café em $1850 .{ }^{1}$

No entanto, é a partir da segunda metade do século XIX e, notadamente, ao longo de todo o século XX, que a urbanização, nos padrões de produção socioeconômicos europeus (com a industrialização crescente), se amplia e o espaço urbanizado começa a ganhar destaque na vida dos cidadãos brasileiros que, até então, se concentravam maciçamente no campo.

Com isso, a realidade urbana do Brasil passa a ser drasticamente alterada. $\mathrm{O}$ inchaço populacional permeia o cotidiano das cidades e a falta de infraestrutura necessária para atender a crescente demanda promove a crise urbana. A reprodução dos aspectos políticos, sociais e econômicos que permeavam a vida no campo passa a confrontar-se com os problemas característicos das cidades sem planejamento urbano, dando origem ao que Florestan Fernandes intitulou "modernização com atraso".

Para citar, com propriedade, os problemas sociais que compõem o rol de influências decisivas para a atual crise urbana vivida pelas cidades brasileiras, pode-se elencar: o patrimonialismo e o clientelismo fundados nas raízes coloniais do Brasil; a desigualdade social, a violência e a industrialização baseada em baixos salários; o contraste oriundo da coexistência entre a "cidade legal", que concentra maiores investimentos públicos e cuja fiscalização sobre o uso do solo se dá com maior intensidade e a "cidade ilegal" composta por áreas irregulares, que pouco interessam ao mercado imobiliário e na qual o poder público pouco investe para a realização dos direitos citadinos.

A cidade "ilegal" constitui única solução para a parcela da população que não possui recursos financeiros para adquirir residências em áreas legalmente regulares e, por isso, se alocam em assentamentos precários e recorrem a construções de imóveis sem planejamento e estrutura material necessária para a construção da cidade.

Os resultados desse processo de marginalidade sócio-urbana são de grandes proporções e promovem uma ocupação predatória e irracional do solo urbano, ensejando catástrofes sócio-ambientais como enchentes, epidemias, desmoronamentos, poluição, dentre outras. O problema expande-se, quando considerado o crescente processo de deslegitimação social da autoridade pública, seja por sua omissão no que tange à realização de direitos, seja pala descrença social, fruto da corrupção praticada pelos representantes políticos do povo.

Nesse cenário de total desrespeito aos direitos humanos e fundamentais e principalmente ao princípio da dignidade da pessoa humana, que é o fundamento da República Federativa do Brasil, o planejamento urbano surge, no Ordenamento Jurídico Pátrio, com a finalidade de minimizar os impactos do crescimento desordenado das cidades

1 Conforme LEAL, Rogério Gesta. Direito urbanístico: condições e possibilidades da Constituição do espaço urbano. Rio de Janeiro: Renovar, 2003. p 17 e 18. 
e também no sentido de oferecer à população recursos que, juridicamente, se traduzem na materialidade do direito à cidade sustentável, colaborando para o amplo respeito à dignidade humana. Nesse sentido destaca Celso Antonio Pacheco Fiorillo:

Marcado pela necessidade de acomodar quase 170 milhões de seres humanos e convivendo com realidades que apontam a existência de mais de um milhão de pessoas em algumas capitais do país, o Brasil convive com a formação de uma cidade irregular ao lado da regular, obrigando a considerar, nos dia de hoje, uma realidade no campo jurídico que nasce com o regramento constitucional (Constituição Federal de 1988), visando superar as discriminações sociais da cidade pós-liberal e dar a todos os brasileiros e estrangeiros que aqui residem os benefícios de um meio ambiente artificial cientificamente concebido.(FIORILLO, 2009, p. 348)

Porem conceber cientificamente os espaços das cidades brasileiras, ou seja, racionalizar a cidade nos moldes científico e planejar os seus novos rumos em consonância com as diferentes vertentes da sociedade, é tarefa árdua que reclama por soluções eficientes e democráticas, a fim de superar as barreiras impostas pela cultura da falta de planejamento, vencendo o dualismo existente entre a cidade urbanizada e a precária (regular e a irregular), a incluída e a excluída da realização dos direitos de cidadania. ${ }^{2}$

Com aporte no Direito Urbanístico, as saídas por meio da legislação e da atuação dos juristas encontram inspiração e legitimidade na Constituição da República Federativa do Brasil de 1988, que inova ao reservar em sue teto um capítulo específico para tratar de política urbana e ao trazer institutos importantíssimos de Direito Urbanístico, a exemplo do Estatuto da Cidade (Lei n. 10.257/2001) e do Plano Diretor Municipal (legislação local), que deram novos contornos à regulamentação das normas jusurbanísticas, com a missão de promover o desenvolvimento urbano sustentável e superar a atual crise que degenera o desenvolvimento das cidades brasileiras.

2. Dignidade da pessoa humana no contexto urbano: o direito à cidade

A cidade, espaço essencialmente político, filosófico, cultural e social, desafia os especialistas quanto à sua definição por se manifestar nas mais diversas formas possíveis. Servem-se os estudiosos, na tentativa de defini-las de vários critérios como o demográfico, o econômico e a pluralidade de sistemas (organizações públicas, comerciais, industriais etc.).

O esforço jurídico doutrinário, no sentido de encontrar uma definição para cidade, fundamenta-se nas possíveis dimensões que os direitos inerentes às cidades podem acarretar a partir da sua definição. Com isso, diante da incompatibilidade de algumas

2 Nesse sentido, têm-se os ensinamentos de MARICATO, Emília. Brasil, cidades: alternativas para a crise urbana. 2. ed. Petrópolis: Editora Vozes, 2002. 
definições de cidade com a ordenação jurídica, é decisiva a contribuição do jurista Celso Antonio Pacheco Fiorillo:

O meio ambiente artificial é compreendido pelo espaço urbano construído, consiste no conjunto de edificações (chamado de espaço urbano fechado), e pelos equipamentos públicos (espaço urbano aberto). Dessa forma, todos os espaços construídos bem como todos os espaços habitáveis pelo homem compõem o meio ambiente artificial.

Com isso, verificamos que este aspecto do meio ambiente está diretamente relacionado ao conceito de cidade, que passou a ter natureza jurídica ambiental não só em face do que estabeleceu a Constituição Federal de 1988, mas particularmente com o Estatuto da Cidade(Lei n. 10.257/2001), porque, como já visto o vocábulo "urbano", do latim urbs, urbis, significa cidade e por extensão, os habitantes desta. (FIORILLO, 2009, p. 339)

Em continuidade ao raciocínio supra-exposto o eminente jurista, através de uma exposição extremamente oportuna, esclarece que o termo "urbano" qualifica todos os espaços habitáveis, logo contem no seu bojo o conceito de rural, este entendimento se coaduna com os cânones do direito fundamental à cidade sustentável, uma vez que o pleno acesso à cidade sustentável direciona-se a todos espaços habitáveis, sendo assim, passa-se a reproduzir o que expõe Fiorillo:

Destarte, o termo "urbano" não evidencia um contraste
com "campo" ou "rural", porquanto qualifica algo que
se refere a todos os espaços habitáveis, "não se opondo a
rural, conceito que nele se contem; possui, possui, pois,
uma natureza ligada ao conceito de território". (FIORILLO,
2009, p. 339)

Para compor o cenário jurídico-doutrinário é forçosa, também, a contribuição que proporcionada pelo jurista José Afonso da Silva no sentido de esclarecer sobre a concepção jurídica de cidade, como passa a reproduzir:

José Afonso da Silva que considera esta "todo centro populacional que possui unidades edilícias - ou seja, o conjunto de edificações em que os membros da coletividade moram ou desenvolvem suas atividades produtivas, comerciais, industriais ou intelectuais e equipamentos públicos - ou seja bens públicos e sociais criados para servir às unidades edilícias e destinados à satisfação das necessidades de que os habitantes não podem prover-se diretamente e por sua própria conta". (SILVA, 2008, p. 26)

A partir dos esclarecedores ensinamentos dos professores supracitados, conclui-se que o direito fundamental à cidade sustentável não se restringe aos espaços maciçamente urbanizados, mas também implica no amplo acesso aos mecanismos citadinos nos espaços habitáveis, destinando-se a todos os cidadãos, sejam eles residentes dos espaços maciçamente urbanizados, rurais ou semi-rurais. 
Nesse diapasão, ressalta-se a característica de universalidade da titularidade do direito fundamental à cidade sustentável, visto que se destina a todos os que se encontram sob a esfera das cidades brasileiras. Toda pessoa, seja ela habitante de espaço rural, semi-rural ou amplamente urbanizado, possui direito à cidade, ou seja, possui direito de acesso aos mecanismos assegurados pelo direito fundamental à cidade sustentável, uma vez que, ter acesso ao saneamento básico, assistência médica e escola próxima à residência não deve configurar-se privilégio das pessoas cujas residências se localizam em espaços considerados "urbanos e regulares", a todos pertence o direito á cidade.

No Brasil, a política de desenvolvimento urbano - impulsionada pelos pilares do ideário reformista, trazidos pelo Movimento Nacional de Reforma Urbana e incorporada pela Constituição de 1988 - tem proporcionado uma série de mudanças paradigmáticas, rompendo com diversos padrões que, até então, dominavam a concepção jurídica de propriedade e cidade. ${ }^{3}$

A cidade passa, então, a ser compreendida na Ordem Jurídica como espaço cultural e coletivo, cuja função é atender aos interesses dos cidadãos com base nos princípios de justiça social, da função social da cidade e da propriedade.

O conceito de propriedade foi modificado através da ideia de função social que permeia o uso desta no espaço urbano, surgindo daí duas orientações que exercem influências diretas na Ciência Jurídica: a função social da propriedade e a função social da cidade. Essas orientações têm revigorado o Direito brasileiro e que, por meio do Direito Urbanístico, passou a representar instrumentos facilitadores do direito à cidade como Direito Fundamental. (CARRERA, 2005, p. 29-30)

Os fundamentos do direito fundamental à cidade sustentável não se reduzem somente a expressar sua influência jurídica, política ou social, mas também estimula a reflexão sobre a cidade como espaço filosófico, no qual é possível o desenvolvimento das potencialidades humanas e a realização de condições de vida digna para o ser humano.

Com isso, enfrenta-se com mais dinamismo o grande desafio de romper com o atual delineamento das cidades brasileiras, que se baseiam na dualidade entre cidade legal e cidade ilegal, resultado da ausência de canais democráticos de participação política no espaço das cidades, da insuficiência de políticas públicas redistributivas, sustentáveis, inclusivas e no desrespeito à dignidade da pessoa humana.

O direito à cidade sustentável é o eixo central do Direito Urbanístico para onde convergem outros direitos fundamentais, não se restringindo somente na construção de moradias, para os que não a possui, e na canalização de investimentos para a criação de empregos, fato que, se isoladamente fossem aplicados à realidade atual das cidades brasileiras, já seria um grande avanço. Ele compreende também, a efetivação de direitos

3 Informações mais detalhadas podem ser encontradas LEAL, Rogério Gesta. Direito urbanístico: condições e possibilidades da constituição do espaço urbano. Rio de Janeiro: Renovar, 2003. 
civis e sociais, a exemplos do acesso aos meios de transportes públicos amplos e inclusivos, do sistema de educação e de proteção à saúde universal, gratuito e de qualidade, do saneamento básico sustentável para toda a população e a promoção/proteção do meio ambiente equilibrado e sustentável, além de segurança pública ampla e competente e lazer disponível a todos. ${ }^{4}$

$\mathrm{O}$ atual engajamento jurídico e político no que tange ao desenvolvimento dos espaços urbanos e do direito à cidade sustentável, transcende as esferas municipais, estaduais e federais passando também a despertar interesse internacional. Nesse sentido o direito à cidade foi reconhecido como direito humano pela comunidade internacional, sob influência de mobilização e ventos ocorridos pelo mundo inteiro, tendo especial destaque a conferência ECO/92 realizada no Rio de janeiro, da qual resultou a Agenda 21, tem-se como relevante, também a Agenda Habitat, documento resultante da Conferência Habitat II, em Istambul, no ano de 1996 e a Carta Mundial pelo Direito à Cidade.

$\mathrm{O}$ texto da Carta Mundial pelo Direito à Cidade, aprovada no Fórum Social Mundial em 2005, esclarece que o:

Direito à Cidade, definido como o usufruto equitativo das cidades dentro dos princípios de sustentabilidade e justiça social. É compreendido como um direito coletivo dos habitantes das cidades, em especial dos grupos vulneráveis e desfavorecidos que lhes confere a legitimidade de ação e organização com base nos seus usos e costumes, para obterem o pleno exercício do direito a um padrão de vida adequado (...). $\mathrm{O}$ direito à cidade é interligado e interdependente a todos os direitos humanos internacionalmente reconhecidos, concebidos integralmente (...). ${ }^{5}$

Com notória relevância o direito à cidade sustentável propõe uma nova forma de se pensar o espaço da cidade, baseando-se em mecanismos de cooperação entre os diferentes atores sociais, gestão democrática da cidade e dignidade da pessoa humana. Implica em uma série de transformações nos padrões de relações humanas, consumo, produção e apropriação do solo e dos recursos naturais. As pessoas se tornam centro das preocupações, competindo às ações públicas guiar-se pelo pleno direito a qualidade de vida para todos.

\footnotetext{
$4 \quad$ Nesse sentido ler texto de JARDIM, Zélia Leocádia da Trindade. Regulamentação da política urbana e garantia do direito à cidade. 2007.

5 Carta Mundial pelo Direito à Cidade. Documento produzido através do Fórum Social das Américas - Quito - Julho 2004, Fórum Mundial Urbano - Barcelona - Setembro 2004 e V Fórum Social Mundial - Porto Alegre - Janeiro 2005.
} 
4. Direito à cidade e os desafios da sustentabilidade urbana

O direito à cidade inserido no contexto do Estado Democrático de Direito qualifica-se pelo princípio da sustentabilidade urbana e envolve categorias e conceitos que, conforme demonstrados alhures, repercutem diretamente na dignidade da pessoa humana ao passo que busca-se efetivar direitos fundamentais que possibilitam a maximização das potencialidades humanas nos espaços citadinos.

Sendo assim, no rol dos desafios atinentes ao estado pós-liberal, viver em um ambiente citadino sustentável envolve questões que não se restringem somente as relações entre seres humanos e meio ambiente ecologicamente equilibrado, este constitui um dos seus objetivos primordiais, porem não é o único, sustentabilidade urbana engloba, também, a superação de mazelas sociais a exemplo da busca pelo equilíbrio que deve existir entre os diferentes fatores sociais de poder, inclusão cidadã das camadas sociais historicamente excluídas, através da efetivação dos direitos citadinos promotores de dignidade da pessoa humana, e principalmente, visa contribuir na formação de uma identidade social que só passará a ser desenvolvida quando a população "urbana" se reconhecer como construtor e principal destinatário da cidade e, consequentemente, dos mecanismos citadinos. $\mathrm{O}$ direito fundamental à cidade sustentável visa alcançar a harmonização entre as diversas vertentes aludidas, que traduz-se basicamente em sustentabilidade, através do principio da sustentabilidade urbana aliado ao princípio da gestão democrática da cidade, que impõe a criação de órgão deliberativo composto pelos diversos setores da sociedade para a governança local.

A sustentabilidade urbano-ambiental é fator determinante e diferencial da atual política de desenvolvimento urbano, pois a exemplo do que afirma Fiorillo:

O uso da propriedade está condicionado ao ambiente cultural, meio ambiente do trabalho e meio ambiente natural da mesma maneira que está, diretamente por força do Estatuto da Cidade, ao meio ambiente artificial, fundamento da lei n. 10.257/2001. Sendo a mais importante norma regulamentadora do meio ambiente artificial, o Estatuto da Cidade, ao ter como objetivo ordenar o pleno desenvolvimento das funções da cidade e da propriedade urbana, mediante algumas diretrizes gerais, criou a garantia do direito a cidade sustentável.(FIORILLO, 2009, p. 354)

Os espaços citadinos historicamente oferecem mecanismos promotores de melhores condições de vida, o que tem atraído milhares de pessoas para os espaços das cidades e o resultado desse processo migratório traduz-se em crise urbana. Por isso, a ampliação trazida pela dimensão do direito à cidade sustentável promove possibilidades de inversão desse cenário, ao oferecer à população rural meios de amplo acesso a mecanismos antes restritos aos habitantes dos centros urbanos, promovendo assim o desenvolvimento humano em equilíbrio com respeito à dignidade da pessoa humana e ao meio ambiente, 
fator que estabelece um novo sistema sustentável, sem que, para isso, seja preciso migrar do campo para os grandes centros urbanos.

Sendo assim, o principio da sustentabilidade urbana, inserido no contexto da cidade sustentável, implica na maximização das potencialidades humanas em consonância com respeito ao meio essencialmente plural e complexo em que se constituem as cidades e ao meio ambiente. É a constante busca por equilíbrio que deve existir entre os diferentes atores sociais, fundamentando-se na justiça social que se contrapõe ao processo de exclusão historicamente propagado no Brasil. Reside na promoção da qualidade de vida dos habitantes e no desenvolvimento econômico compatível com a preservação sustentável dos recursos naturais, ao passo que propaga a ampliação de soluções em combate ao aumento da pobreza que ocorre em escala mundial.

$\mathrm{O}$ arquiteto e urbanista peruano Eduardo Alva no livro Metrópoles (In) Sustentáveis traz uma importante colaboração para a compreensão da cidade sustentável nas suas mais variadas dimensões, sendo assim o professor esclarece que:

Uma cidade sustentável depende da capacidade de reorganizar os espaços, gerir novas economias externas, eliminar as deseconomias de aglomeração, melhorar a qualidade de vida das populações e superar as desigualdade socioeconômicas para o crescimento econômico. (ALVA, 1991, p.15)

A sustentabilidade urbano-ambiental se impõe como fator imprescindível diante da atual crise urbana propagada mundialmente nos mais variados espaços citadinos. Planejar a construção das cidades e buscar alternativas para promover o equilíbrio que demanda o conceito de cidade sustentável é o grande desafio a ser superado pelos atores sociais do século XXI.

5. Princípios Orientadores do Desenvolvimento Urbano e os Principais Institutos Jusurbanísticos em vigor pós-constituição de 1988

Pensar os espaços citadinos e buscar alternativas para um desenvolvimento sustentável que possibilite a realização dos pilares do Estado Democrático de Direito em harmonia com o respeito à dignidade da pessoa humana é um grande desafio, árduo no que tange a sua concretização, principalmente quando nos voltamos para realidade do país e consideramos os níveis atuais de consciência social e atuação dos representantes políticos do povo brasileiro.

Porém a atual crise que coloca em estado de caos a vida urbana e põe em risco a sobrevivência humana e a existência do planeta reclama por soluções e novos posicionamentos, que não estão adstritos somente aos poderes de governança estatal, mas também se estende a sociedade civil organizada e ao setor privado que deve observar o seu compromisso social. 
Nesse sentido, diante da complexa rede das relações humanas estabelecidas nos espaços das cidades o planejamento urbano busca fundamentar-se em princípios que possibilitem o exercício dos diretos de cidadania aliados ao respeito às minorias e à pluralidade étnica, sexual e cultural.

Por esse viés a política de desenvolvimento urbano, no seu aspecto jurídico, é orientada por princípios como os da função social da cidade, função social da propriedade, exercício pleno da cidadania, igualdade material e não discriminação, proteção especial a segmentos sociais excluídos e vulneráveis, impulso à economia solidária e às políticas impositivas e progressivas, compromisso social do setor privado, sustentabilidade urbanoambiental, gestão democrática da cidade e vida digna nos espaços da cidade. (CARRERA, 2005:45)

Por sua vez o principio das gestões democráticas da cidade, é extremamente importante para os novos rumos dos Municípios brasileiros, pois se direciona para o fortalecimento do papel dos cidadãos em sua atuação política, principalmente nos Municípios, ao impulsionar a realização de políticas públicas que possibilitem o direito ao amplo debate e poder decisão nas questões urbanas. Significa a democratização de governança local, ofertar a segmentos historicamente excluídos o direito de se manifestar acerca dos problemas sociais que lhes afetam cotidianamente. Esse princípio busca proporcionar a todos os cidadãos o direito de participar na defesa de seus interesses, promovendo mecanismos de participação popular para a concreção de vida digna para todos.

O Estatuto da Cidade com o escopo de disciplinar o princípio da gestão democrática da cidade assim estabelece:

Art. 43. Para garantir a gestão democrática da cidade, deverão ser utilizados, entre outros, os seguintes instrumentos:

I - órgãos colegiados de política urbana, nos níveis nacional, estadual e municipal;

II - debates, audiências e consultas públicas;

III - conferências sobre assuntos de interesse urbano, nos níveis nacional, estadual e municipal;

IV - iniciativa popular de projeto de lei e de planos, programas e projetos de desenvolvimento urbano;

Art. 44. No âmbito municipal, a gestão orçamentária participativa de que trata a alínea $\mathrm{f}$ do inciso III do art. $4^{\circ}$ desta Lei incluirá a realização de debates, audiências e consultas públicas sobre as propostas do plano plurianual, da lei de diretrizes orçamentárias e do orçamento anual, 
como condição obrigatória para sua aprovação pela Câmara Municipal.

Art. 45. Os organismos gestores das regiões metropolitanas e aglomerações urbanas incluirão obrigatória e significativa participação da população e de associações representativas dos vários segmentos da comunidade, de modo a garantir o controle direto de suas atividades e o pleno exercício da cidadania. (Lei Federal 10.257/2001)

Estes e os demais princípios relacionados acima são reflexos do processo de reconhecimento e positivação das normas que, atualmente, regem o Direito Urbanístico brasileiro e que são frutos de diversas conquistas político-sociais, a começar pela previsão normativa na Constituição da República Federativa do Brasil sobre a política urbana (arts. 182 e 193), fato inédito na seara jurídica do país. A CRFB prevê, no capitulo referente à política urbana, a elaboração de institutos jurídicos de âmbito federal e municipal para regulamentar o planejamento urbano.

No tocante à regulação federal a Lei Federal n. 10.257/2001, que em seu art. $1^{\circ}$, parágrafo único, se autodenomina "Estatuto da Cidade", é instrumento jus-urbanístico, cujo objetivo consiste em traçar diretrizes gerais pertinentes à política de desenvolvimento urbano, em nível nacional. Estabelece de forma programática estratégias, instrumentos e ações que o poder público (de todos os níveis federativos) deverá implementar, isoladamente ou em cooperação com os demais segmentos da sociedade no intuito de alcançar uma ordem urbana fundamentada na realização das funções sociais da cidade e da propriedade urbana. ${ }^{6}$

No Estatuto da Cidade encontram-se importantes instrumentos urbanísticos, a exemplo, do direito de superfície, a concessão do direito real de uso, edificação e o parcelamento compulsório, o direito de preempção, a urbanização consorciada, o plano diretor, o imposto predial progressivo, a outorga onerosa do direito de construir, a usucapião especial urbano, a concessão especial para fins de moradia, o estudo do impacto de vizinhança, o consorcio imobiliário e a gestão democrática da Cidade.

Portanto, a referida norma federal constitui-se em principal marco regulatório infraconstitucional do Direito Urbanístico pátrio, insígnia da nova Ordem Constitucional do Estado Democrático de Direito e que serve de verdadeira carta de princípios e instrumentos para a elaboração de leis federais, estaduais e municipais sobre planejamento das cidades, pois vai ao encontro das diversas conquista da cidadania brasileira. (SILVA, 2006:59-60)

6 Vide CARVAlHO FilHO, José dos Santos. Comentário ao Estatuto da Cidade: Lei 10.257, de 10.7.2001. Rio de Janeiro: Editora Lumen Juris, 2005. 
Entretanto, como já é de conhecimento de todos, a promulgação de um diploma legal é somente o começo de um longo e árduo caminho a ser percorrido rumo a implementação, fazer com que os princípios e diretrizes estabelecidos pelo Estatuto da Cidade sejam realizados é o grande desafio para o poder público e para a sociedade brasileira.

O poder público possui grande e incomparável responsabilidade na realização dos direitos estabelecidos no Ordenamento Jurídico pátrio, mas o que a Política de Desenvolvimento Urbano atualmente propõe, consubstanciada pelo Constituição, Estatuto da Cidade e Plano Diretor Municipal, é uma gestão democrática com base no elo cooperativo entre os cidadãos e o Estado. É no espaço das cidades que as potencialidades humanas se desenvolvem e por isso não se pode prescindir na construção desta, de efetiva participação de todos, ao povo cabe cooperar na concretização do planejamento urbano e atuar na constante fiscalização, a cidade deve ser pensada por todos e para todos.

As conquistas de âmbito jus-urbanísticos alcançadas atualmente são decisivas e extremamente relevantes para delinear os novos rumos da cidadania brasileira. Porém a positivação dos referidos direitos significa início de trajetória e nunca fim, é somente pelo viés da consciência social e engajamento político da população que a realização desses direitos se expandirá para todos. Por conta disto é que a importância do Plano Diretor local se revela ímpar diante da necessidade de planejar localmente os espaços habitáveis, fato que se revelará conceitualmente no item que segue.

6. Planejamento urbano na ótica da lei: os Planos Diretores Municipais.

Conforme demonstrado o planejamento urbano municipal deve ser caracterizado por promover a integração entre as diretrizes gerais estabelecidas em leis hierarquicamente superiores, a saber, a Constituição da República Federativa do Brasil de 1988 e o Estatuto da Cidade, conjugando-as com as principais características socioculturais existentes no Município.

Diante dessa dialética normativo-social é valido salientar que, na realidade local, o Plano Diretor Municipal assume o papel de realização do direito fundamental a cidade sustentável, e tem a sua validade adstrita à observância dos princípios constitucionais da gestão democrática, da justiça social, da função social da propriedade e da cidade, da sustentabilidade urbano-ambiental e, principalmente, da dignidade da pessoa humana, sob pena de ser eivado de inconstitucionalidade.

Os Municípios possuem, em especial, grande responsabilidade na execução da Política Urbana, já que a eles foi outorgado pela Constituição da República Federativa do Brasil, em seu art. 182, o desafio de elaborar, instituir mediante lei e executar, cooperativamente, o Plano Diretor Municipal, que se traduz em legislação principal no processo de concretização da política de desenvolvimento e expansão urbana (LEAL, 2003:143-144). 
O Plano Diretor, enquanto lei municipal e mecanismo técnico e político, deve regulamentar, essencialmente, os aspectos físicos, referentes à ocupação do solo, assim como lançar diretrizes baseando-se em fatores sociais, no intuito de garantir inclusão e vida digna para seus habitantes. Para tanto, e por força da Carta Magna de 1988, a legislação se tornou obrigatória para cidades que possuem mais de 20 (vinte) mil habitantes, porém as que não possuem esse quantitativo populacional não estão dispensados da observância e efetivação dos princípios constitucionais pertinentes à política urbana até porque é obrigação de todos, sejam entidades políticas ou sociedade, desenvolver de maneira sustentável os ambientes urbanos, ambientais e coletivos. (CARVALHO FILHO, 2005: 263-266)

O plano diretor é instrumento básico para delinear as diretrizes jusurbanísticas do município e consoante o previsto no art. $182, \S 2^{\circ}$ da Constituição Federal "a propriedade urbana cumpre com a sua função social quando atende às exigências fundamentais de ordenação da cidade expressa no plano diretor", tal disposição impõe a função da propriedade urbana adstrita ao cumprimento das diretrizes imposta pelo Plano Diretor, fato que expõe a relevância do planejamento urbanístico municipal independente da densidade populacional existente no Município.

A função social da cidade é um grande marco no processo de transformações jurídicas que ocorridas no Brasil com o advento do Estado Democrático de Direito, e se caracteriza por promover o uso racional e sustentável do espaço urbano, irradiando em todos os espaços citadinos a necessidade de haver consciência social, para que os cidadãos apropriem-se do território, democratizando os mecanismo de poder, produção, cultura e qualidade de vida, fundamentando-se nos parâmetros de justiça social e dignidade da pessoa humana.

Compete ao Plano Diretor local primar, em nível municipal, pela efetiva instalação dos pilares do Estado Democrático de Direito. E para alcançar tal desiderato, deve se direcionar para o amplo respeito à dignidade da pessoa humana, realizando um complexo normativo que possibilite a realização dos direitos fundamentais e humanos, a construção de uma sociedade mais livre, justa e solidária, o desenvolvimento de cidades sustentáveis, a inclusão social e a atuação constatem dos cidadãos na condução de seus destinos, através de gestões democráticas.

Os mecanismos técnicos componentes do Plano Diretor municipal se revestem de natureza legal, devendo o projeto de lei ser aprovado pelo legislativo municipal, na forma do devido processo legal. Sendo assim o Plano Diretor municipal poderá ser alterado, na forma da lei, de acordo com o interesse público, conforme diretrizes estabelecidas pela Lei Federal n. 10.257/2001, que prevê a revisão do plano, pelo menos, a cada dez anos, sob pena de se caracterizar improbidade administrativa do prefeito nos termos do art. 52, VII da mencionada lei. 
No que tange ao orçamento destinado à execução do plano diretor, o legislador estatutário instituiu que o Plano Plurianual, o Orçamento Anual e as Diretrizes Orçamentárias deverão incorporar os comandos e as prioridades estabelecidas no Plano Diretor municipal, competindo ao Poder Executivo municipal a edição de Regulamentos e propositura de leis que tornem exequível o Plano Diretor municipal com o escopo de evitar, por Poder Público do Município, a inobservância e inexecução do mencionado instrumento legal-estratégico.

Conclusão

A necessidade humana de estar em sociedade, interagindo com outros seres humanos e desenvolvendo suas potencialidades em um sistema de divisão de tarefas (cooperação), os leva a escolher os espaços das cidades para viver. Diante da demanda, altamente crescente, as cidades que, via de regra, não possuem planejamento e estrutura adequada para proporcionar aos seus habitantes condições de desenvolverse com dignidade, enfrentam graves problemas socioeconômicos, cuja marca maior é a segregação, uma vez que, os mecanismos citadinos são para poucos, e os espaços das cidades encontram-se permeados pelo completo desrespeito aos direitos humanos e fundamentais.

Sendo assim, é nesse cenário, onde não há mais espaços para a apatia e no qual os problemas sociais afetam diretamente a todos, que surge a necessidade de um enérgico posicionamento jurídico, estatal e social, a fim de superar "velhos" problemas e se preparar para os que consequentemente irão surgir. Em resposta a tal situação, institutos jus-urbanísticos a exemplo do direito fundamental a cidade sustentável, a função social da cidade e da propriedade urbana, o Estatuto da Cidade e Plano Diretor municipal, se propõem a repensar os espaços habitáveis e fornecer mecanismo para a otimização dos recursos conciliando-os com o amplo respeito à dignidade da pessoa humana.

Promover a realização desses institutos é tarefa de todos, em especial do Poder Público municipal, uma vez que, a este foi atribuída a competência de promover, em sede local, o direito fundamental a cidade e a função social da cidade, através da realização do Plano Diretor municipal. Atualmente a maioria dos Municípios brasileiros já positivaram o Plano Diretor municipal, concretizá-los oferecendo aos cidadãos o direito fundamental a uma cidade sustentável, que se caracteriza por tornar acessível a todos mecanismos de amplo respeito aos Direitos Fundamentais e a dignidade da pessoa humana, é o próximo passo.

A efetivação das aludidas norma jurídicas esta vinculada a uma série de transformações que envolvem diversos fatores como a tomada de consciência dos cidadãos, assim como a efetiva cooperação entre o setor público e o privado, pois a conservação das cidades, com o efetivo controle da violência e problemas similares e a realização 
dos direitos fundamentais interessa a todos. Por isso embora a responsabilidade caiba, precipuamente ao ente estatal, cuja finalidade é a realização de direitos, a participação de todos, seja no sentido dar sugestões ou cobrar a realização dos seus direitos, é pressuposto para a realização do Direito Fundamental a cidade sustentável.

Ilhéus, julho de 2011.

\section{Referências}

ALEXY, Robert. Teoria dos direitos fundamentais. Trad. Virgílio Afonso da Silva. São Paulo: Malheiros, 2008.

ALVA, Eduardo Neiva. Metrópoles (in) sustentáveis. Rio de Janeiro: Relume Damará, 1997.

CAPPELLETTI, Mauro. O controle judicial de constitucionalidade das leis no direito comparado. 2. ed. Porto Alegre: Sérgio Antonio Fabris Editor,1999.

CARVALHO FILHO, José dos Santos. Comentário ao Estatuto da Cidade: Lei 10.257, de 10.7.2001. Rio de Janeiro: Lumen Juris, 2005.

COUTINHO, Ronaldo; BONIZZATO, Luigi. Direito da cidade: novas concepções sobre as relações jurídicas no espaço social urbano. Rio de Janeiro: Lumen Juris, 2007.

FERNANDES, Edésio. Direito do urbanismo: entre a "cidade legal" e a "cidade ilegal". Belo Horizonte : Del Rey, 1998.

FIORILlo, Celso Antonio Pacheco. Curso de direito ambiental brasileiro. São Paulo: Saraiva, 2009.

HABERLE, Peter. Hermenêutica constitucional: a sociedade aberta dos interpretes da constituição: contribuição para a interpretação pluralista e "procedimental" da Constituição. Trad. Gilmar Mendes. Porto Alegre: Sérgio Antonio Fabris Editor, 1997.

LASSALLE, Fernando. A essência da Constituição. Tradução de Walter Stronner. Rio de Janeiro: Liber Juris, 1988.

LEAL, Rogério Gesta. Direito urbanístico: condições e possibilidades da Constituição do espaço urbano. Rio de Janeiro: Renovar, 2003.

LIRA, Ricardo Pereira. Elementos de direito urbanístico. Rio de Janeiro: Renovar, 1999.

MENDES, Gilmar Ferreira; COELHO, Inocêncio Mártires; BRANCO, Paulo Gustavo Gonet. Curso de direito constitucional. 3. ed., rev. e atual. São Paulo: Saraiva, 2008.

SARMENTO,Daniel. A ponderação de interesses na constituição federal. Rio de Janeiro: Lumen Juris, 2002.

SILVA, Carlos Henrique Dantas da. Plano diretor: teoria e prática. São Paulo: Saraiva, 2008. 